\title{
CD4 T Cell Determinants in West Nile Virus Disease and Asymptomatic Infection
}

\author{
Maximilian Koblischke ${ }^{1}$, Felicia S. Spitzer ${ }^{1}$, David M. Florian ${ }^{1}$, Stephan W. Aberle ${ }^{1}$, \\ Stefan Malafa ${ }^{1}$, Ingrid Fae ${ }^{2}$, Irene Cassaniti ${ }^{3,4}$, Christof Jungbauer ${ }^{5}$, Bernhard Knapp ${ }^{6}$, \\ Hermann Laferl ${ }^{7}$, Gottfried Fischer ${ }^{2}$, Fausto Baldanti ${ }^{3,4}{ }^{4}$, Karin Stiasny ${ }^{1}$, Franz X. Heinz ${ }^{1}$ \\ and Judith H. Aberle ${ }^{1 *}$ \\ ${ }^{1}$ Center for Virology, Medical University of Vienna, Vienna, Austria, ${ }^{2}$ Department of Blood Group Serology and Transfusion \\ Medicine, Medical University of Vienna, Vienna, Austria, ${ }^{3}$ Molecular Virology Unit, Microbiology and Virology Department, \\ Fondazione IRCCS Policlinico San Matteo, Pavia, Italy, ${ }^{4}$ Department of Clinical, Surgical, Diagnostic and Pediatric Sciences, \\ University of Pavia, Pavia, Italy, ${ }^{5}$ Blood Service for Vienna, Lower Austria and Burgenland, Austrian Red Cross, Vienna, \\ Austria, ${ }^{6}$ Data Science Section, Symptoma GmbH, Vienna, Austria, ${ }^{7}$ Sozialmedizinisches Zentrum Süd, \\ Kaiser-Franz-Josef-Spital, Vienna, Austria
}

West Nile (WN) virus infection of humans is frequently asymptomatic, but can also lead to WN fever or neuroinvasive disease. CD4T cells and B cells are critical in the defense against WN virus, and neutralizing antibodies, which are directed against the viral glycoprotein $\mathrm{E}$, are an accepted correlate of protection. For the efficient production of these antibodies, B cells interact directly with CD4 helper T cells that recognize peptides from $E$ or the two other structural proteins (capsid-C and membrane-prM/M) of the virus. However, the specific protein sites yielding such helper epitopes remain unknown. Here, we explored the CD4T cell response in humans after WN virus infection using a comprehensive library of overlapping peptides covering all three structural proteins. By measuring $T$ cell responses in 29 individuals with either WN virus disease or asymptomatic infection, we showed that CD4 T cells focus on peptides in specific structural elements of $\mathrm{C}$ and at the exposed surface of the pre-and postfusion forms of the $\mathrm{E}$ protein. Our data indicate that these immunodominant epitopes are recognized in the context of multiple different HLA molecules. Furthermore, we observed that immunodominant antigen regions are structurally conserved and similarly targeted in other mosquito-borne flaviviruses, including dengue, yellow fever, and Zika viruses. Together, these findings indicate a strong impact of virion protein structure on epitope selection and antigenicity, which is an important issue to consider in future vaccine design.

Keywords: West Nile virus, flavivirus, CD4 T cell, immunodominance, epitope, West Nile patients

\section{INTRODUCTION}

West Nile (WN) virus is a mosquito-borne flavivirus that has caused repeated epidemics in the Americas since its first appearance in 1999, with more than 48,000 documented human cases and $\sim 2,300$ deaths (1). In addition, several recent WN virus outbreaks have been reported in Europe, the largest in 2018, involving over 2,000 human cases in 15 countries (1-3). Although most WN virus infections remain asymptomatic (4), about $20 \%$ of humans develop symptoms of WN fever, 
and about one in 150 develop acute neuroinvasive disease (5). Despite significant disease burden, there is no specific treatment or vaccine against WN virus licensed for human use. Protective immunity to $\mathrm{WN}$ virus has been mainly attributed to neutralizing antibodies, which are essential for the clearance of infection and long-term immunity against disease (6-8). CD4 T cells also play critical roles in the defense against $\mathrm{WN}$ virus, both by promoting protective antibody responses and by direct killing of infected cells $(9,10)$. Despite this central role, the factors influencing the development of effective $\mathrm{WN}$ virus-specific CD4 T cell responses, specifically the sites in virus proteins giving rise to dominant CD4 T cell epitopes, remain unknown.

Like flaviviruses in general, mature $\mathrm{WN}$ virus particles consist of a nucleocapsid, which is composed of the single-stranded RNA genome and multiple copies of the capsid (C) protein, as well as a lipid envelope with two membrane-associated proteins, the membrane $(\mathrm{M})$ protein, and the envelope (E) protein (Figure 1A). The $\mathrm{M}$ protein is generated by proteolytic cleavage of a precursor ( $\mathrm{prM}$ ) that is a component of immature virions (11) (Figure 1A). The E protein contains three distinct domains (domains I-III) and a so-called stem region, followed by two transmembrane domains. Upon entry into host cells, the acidic $\mathrm{pH}$ of the endosome triggers an irreversible conformational change in the $\mathrm{E}$ protein that leads to membrane fusion and converts the metastable pre-fusion dimer into a stable postfusion trimer $(12,13)$. Due to its important cell entry functions, the $\mathrm{E}$ protein is the major target of neutralizing antibodies (68). CD4 T cells provide essential help for potent neutralizing antibody production by direct cell surface interactions with $\mathrm{B}$ cells and the recognition of antigenic peptides presented with major histocompatibility complex class II (MHC II) molecules. Peptides for such direct help can derive from the E protein, recognized by the $B$ cells or the two other structural proteins ( $M$ and $\mathrm{C}$ ) that are co-internalized as part of the virus particle.

The mechanisms influencing peptide presentation are incompletely understood, but a number of factors have been shown to affect the selection of epitopes during different stages of antigen processing. These include protein sequence-related factors, such as protease cleavage sites and MHC binding affinity (14). Furthermore, growing evidence suggests that protein structural features can modulate the efficacy of epitope generation during antigen processing (15-19). In addition, it has been suggested that conformational changes of viral envelope proteins at the early endosomal $\mathrm{pH}$ can influence the processing and presentation of certain peptides (20).

An analysis of CD4 T cell epitopes in the context of the atomic structures of viral protein antigens may therefore provide important clues about how the dominance of certain epitopes is controlled by structural features. Recent studies examining immunodominant epitopes in the context of three-dimensional protein structures have led to the identification of critical

\footnotetext{
Abbreviations: C, capsid; DEN, Dengue; E, envelope; HLA, human leukocyte antigen; JE, Japanese encephalitis; M, membrane; MHC, major histocompatibility complex; PBMCs, peripheral blood mononuclear cells; prM, pre-membrane; TBE, Tick-borne encephalitis; WN, West Nile; WND, West Nile virus disease; YF, Yellow fever.
}

CD4 $\mathrm{T}$ cell epitopes in other flaviviruses, including Zika, yellow fever (YF) and tick-borne encephalitis (TBE) viruses (21-24). Crystallographic and cryo-EM studies have shown that the E proteins of flaviviruses are structurally very similar, whereas their sequences differ by up to $60 \%$ among distantly related flaviviruses (25-30). This combination of structural conservation and sequence divergence provides a perfectly suitable model for examining the role of protein structural features as opposed to sequence in the selection of peptides and the dominance of certain epitope responses.

Here, we exploited this model to obtain insights into the selection of CD4T cell epitopes in $\mathrm{WN}$ virus infection. By measuring responses in 29 individuals with either West Nile virus disease (WND) or asymptomatic infection, we identified 67 peptides in the viral capsid and envelope proteins that were recognized in the context of multiple different HLA II alleles. Although WND patients and asymptomatic subjects displayed differences with respect to the recognition of certain epitopes associated with specific HLA alleles, the overall epitope patterns between these groups were similar. Both in $\mathrm{C}$ and $\mathrm{E}$ proteins, immunodominant epitopes clustered in structurally conserved regions that have also been identified as frequent targets in other mosquito-borne flaviviruses. These data are consistent with an important influence of conserved conformational features in the structural proteins of flaviviruses that shape the specificities and immunodominance of CD4 T cell responses.

\section{MATERIALS AND METHODS}

\section{Study Population}

A total of $29 \mathrm{WN}$ virus-infected subjects were enrolled in this study (Table 1). The cohort consisted of 11 WND patients (age range, 27-65 years; median age, 51 years; 4 female and 7 male) with moderate to severe symptoms (Table 1), as well as 18 asymptomatic blood donors (age range, 34-70 years; median age, 55 years; 3 female and 15 male) who were recruited through routine screening of blood donations performed by the Austrian Red Cross and the Regional Reference Laboratory of the Lombardy Region (Molecular Virology Unit, Fondazione IRCCS Policlinico San Matteo Pavia) in northern Italy.

At the time of diagnosis, 25 out of 29 (86\%) individuals had detectable WN virus RNA in blood samples, and 29 out of $29(100 \%)$ had detectable WN virus IgM (Table 1). WN virus infection was confirmed in all study participants by neutralization tests, as described below. Previous infection with mosquito-borne flaviviruses from other serocomplexes was analyzed by neutralization assays, as described in detail below. At the time of diagnosis, all 29 participants were negative in Zika neutralization tests. In addition, previous DEN virus infection was ruled out in 28 out of 29 subjects using DEN immunoassays after depletion of broadly flavivirus cross-reactive antibodies, as described below. As a control, samples obtained from 10 flavivirus-naïve individuals were analyzed.

\section{Ethics Statement}

The study was performed in accordance with the recommendations of the Declaration of Helsinki, and all 

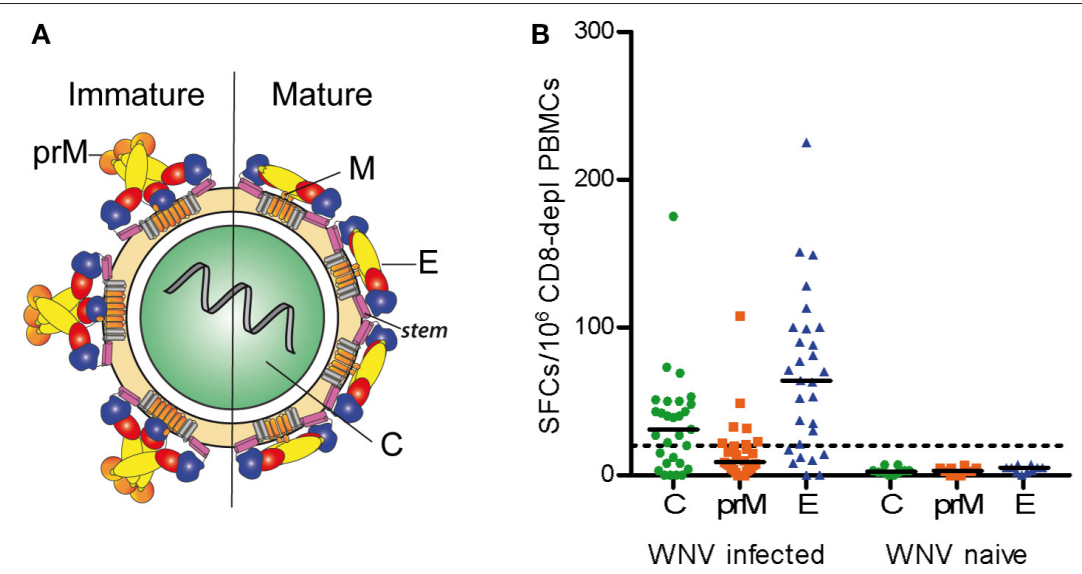

C

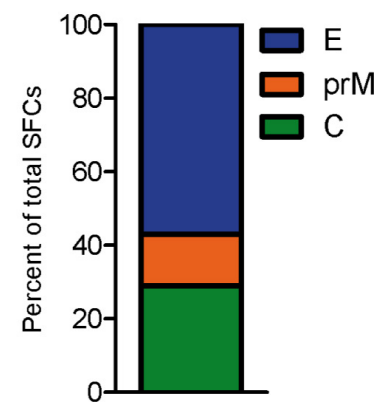

FIGURE 1 | CD4 T Cell Responses to WN Virus. (A) Schematic representation of immature and mature flavivirus particles. The virion contains three structural proteins: $\mathrm{C}$ (capsid), prM (pre-membrane) in immature and M (membrane) in mature virus particles, and $\mathrm{E}$ (envelope). The E protein consists of three domains, DI (red), DII (yellow), DIII (blue), as well as the stem (purple) and transmembrane region (gray). (B) Individual CD4 T cell responses from WN virus-infected subjects and naïve controls to WN virus peptide pools covering the entire sequences of structural proteins C, prM and E, as determined by IL-2 ELISPOT assays. Results are shown as spot forming cells (SFCs) per million CD8-depleted PBMCs. Medians are displayed as black lines. The dashed line represents the cut-off value for assay positivity. (C) Percentage of spots contributed by $\mathrm{C}$, prM and $\mathrm{E}$ in WN virus-infected subjects.

study participants provided written informed consent. The ethics committee of the Medical University of Vienna, Austria, approved the study protocol (approval no. 1295/2016). Patient samples were processed in accordance with biosecurity regulations and institutional safety procedures.

\section{Detection of West Nile Virus RNA}

WN virus PCR was performed as described previously (31). Briefly, WN virus RNA was extracted from plasma, whole blood, serum and/or cerebral spinal fluid using NucliSENS easyMAG extractor (BioMérieux, Marcy l'Etoile, France). For the detection of WN virus lineages 1 and 2, a real-time TaqMan PCR with primers and probe located within the conserved WN virus 3/noncoding region was used (32).

\section{Detection of West Nile Virus IgM}

WN virus-specific IgM antibodies were detected in a capture ELISA using purified formalin-inactivated WN virus (31) and a WN virus-specific monoclonal antibody E16 for detection (33).

\section{Neutralization Tests}

Neutralization tests (NTs) to confirm WN virus infection were performed with follow-up samples from all individuals, as described previously (31). Briefly, duplicates of serial 2-fold dilutions of heat-inactivated serum samples were incubated with 30-60 TCID $_{50}(50 \%$ tissue culture infective dose) of WN virus strain NY99 for $1 \mathrm{~h}$ at $37^{\circ} \mathrm{C}$. Vero cells (ECACC) were added and incubation was continued for $4-6$ days at $37^{\circ} \mathrm{C}$. The presence of infectious (non-neutralized) virus was assessed by microscopic evaluation of cytopathic effects. Virus NT titers were expressed as the reciprocal of the serum dilution required for hundred percent protection against virus-induced cytopathic effects. Virus NT titers $\geq 20$ were considered positive. Zika virus-specific neutralizing antibodies were determined in Vero cells (23). Duplicates of serial 2-fold dilutions of heat-inactivated serum samples were incubated with $30-60 \mathrm{TCID}_{50}$ Zika virus (strain $\mathrm{H} / \mathrm{PF} 2013$ ) for $1 \mathrm{~h}$ at $37^{\circ} \mathrm{C}$. Vero cells were added and incubation was continued for 3-4 days. Virus NT titers were expressed as the reciprocal of the serum dilution required for hundred percent protection against virus-induced cytopathic effects. Virus NT titers $\geq 20$ were considered positive (23). YF and TBE NTs were carried out in baby hamster kidney cells (BHK-21, ATCC) (23, 34). Duplicates of serial 2 -fold dilutions of heat-inactivated serum samples were incubated with YF-17D virus or TBE virus strain Neudoerfl for $1 \mathrm{~h}$ at $37^{\circ} \mathrm{C}$. BHK cells were added and incubation was continued for 3-4 days. YF NT titers were expressed as the reciprocal of the serum dilution required for hundred percent protection against virus-induced cytopathic effects (23). Virus NT titers $\geq 20$ were considered positive. In the case of TBE, the presence of virus was measured in the supernatants using ELISA. Neutralization titers were defined as the reciprocal of the plasma dilution that gave a $90 \%$ reduction in the absorbance readout in the assay compared to the control without antibody (23). Virus NT titers $\geq 10$ were considered positive. Positive NT titers for YF or TBE or both were obtained in $0(0 \%), 21(72 \%)$, and 3 (10\%) cases, respectively. Flavivirus-naïve control samples were negative in neutralization assays. Neutralization assays using infectious virus were performed under biosafety level BSL3.

\section{Antibody Depletion}

Depletion of cross-reactive antibodies and dengue IgG ELISAs (Euroimmun) were performed to rule out previous DEN virus infection (23). Broadly cross-reactive antibodies were depleted from serum samples using a strep-tagged soluble E protein $(\mathrm{sE}$, lacking the stem-anchor region) from Rio Bravo virus (35), coupled to StrepTactin XT spin columns (IBA GmbH, Göttingen, Germany). Residual DEN-IgG reactivity was below the detection limit in 28 of 29 patients, indicating that they were DEN-naïve. In 
TABLE 1 | Characteristics of West Nile virus-infected subjects.

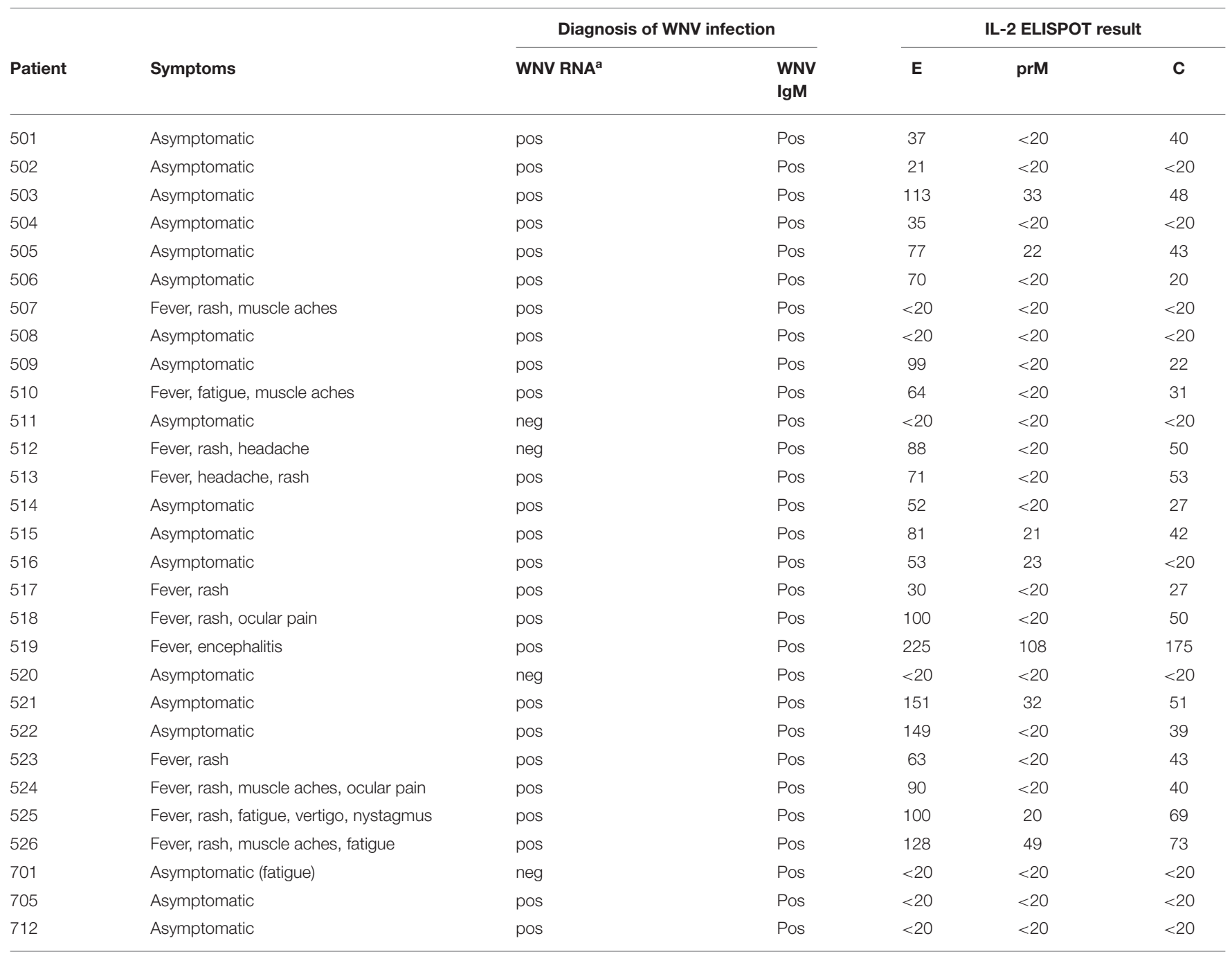

${ }^{a}$ WN virus PCR performed in plasma, whole blood, serum and/or cerebral spinal fluid.

the depleted serum of one donor (\#705) DEN-IgG Abs were not removed by Rio Bravo virus E protein.

\section{Preparation of Blood Samples}

Peripheral blood mononuclear cells (PBMCs) were separated from whole-blood samples using Ficoll-Paque Plus ${ }^{\mathrm{TM}}$ (GE Healthcare) and were cryopreserved in liquid nitrogen, as previously described (23). PBMCs were thawed and depleted of CD8-positive cells using magnetic beads coupled with anti-CD8 antibody and LD columns (Miltenyi Biotec GmbH, Germany), as previously described (24). The depleted PBMCs were incubated overnight in serum-free medium (AIM-V; Gibco) at $37^{\circ} \mathrm{C}$ in $5 \% \mathrm{CO}_{2}$. For use in ELISPOT assays, cells were resuspended at a final concentration of $2 \times 10^{6}$ cells/ ml in AIM-V. The purity and viability of CD8-depleted PBMCs in each sample was assessed using anti-CD8-APC, anti-CD3$\mathrm{PE}$, anti-CD4-PacificBlue ${ }^{\mathrm{TM}}$, and 7-aminoactinomycin D (BD
Bioscience) and flow cytometry (23). After depletion, CD8positive cells were $<1 \%$. Plasma and serum samples were stored at $-20^{\circ} \mathrm{C}$.

\section{Peptides}

Peptides were purchased from JPT Peptide Technologies (Berlin, Germany). Peptide purity was $>70 \%$. Peptides were quantified and verified for correct sequence by JPT, using highperformance liquid chromatography. The average purity was $>85 \%$. Lyophilized peptides were dissolved in dimethyl sulfoxide and diluted in AIM-V medium (23). A total of 190 peptides (15 mer) overlapping by 11 amino acids which cover the entire sequences of $\mathrm{C}, \mathrm{prM}$, and $\mathrm{E}$ from the $\mathrm{WN}$ virus strain Austria/2008 (protein accession code: AGX89731). Three master pools covered the C, prM, or E protein sequences. Matrix pools of $\mathrm{C}(n=10)$ and $\mathrm{E}(n=22)$ contained up to 14 peptides with each peptide present in two distinct pools. All positive results obtained 
with the matrix pools were confirmed by testing the samples with single peptides in independent experiments.

\section{IL-2 ELISPOT Assay}

IL-2 ELISPOT assays were performed as previously described (22-24). Briefly, plates (Merck-Millipore) were coated with 1 $\mu \mathrm{g}$ anti-IL-2 antibody (3445-3-1000, Mabtech). For blocking, RPMI 1640 medium (Sigma) containing 10\% human serum, $1 \%$ penicillin/streptomycin/glutamine (Gibco), and $1 \%$ nonessential amino acids (Sigma) was used. CD8-depleted PBMCs (2 $\times 10^{5}$ / per well) were incubated at $37^{\circ} \mathrm{C}$ and $5 \% \mathrm{CO}_{2}$ for about $45 \mathrm{~h}$ with peptides (final peptide concentration $2 \mu \mathrm{g} / \mathrm{ml}$ ), AIM-V medium (negative control) or phytohemagglutinin (PHA, Sigma) (final concentration $0.5 \mu \mathrm{g} / \mathrm{ml}$, positive control). After washing, spots were developed with $0.05 \mu \mathrm{g}$ biotin-conjugated anti-IL-2 antibody (3445-6-250, Mabtech), streptavidin-coupled alkaline phosphatase (ALP; 1:1000, 3310-10, Mabtech), and 5-bromo4-chloro-3-indolylphosphate/nitroblue tetrazolium (BCIP/NBT; B5655, Sigma). The plates were analyzed using a Bio-Sys Bioreader 5000 Pro-S/BR177 and Bioreader software generation 10. Data were calculated as spot forming cells (SFCs) per $10^{6}$ CD8-depleted PBMCs after subtraction of the spots from the negative control (mean spot number from three to four unstimulated wells). The response to a single peptide was defined positive if the corresponding master pool, matrix pool as well as single-peptide testing yielded $>20$ SFCs per $10^{6}$ CD8-depleted PBMCs $(22,23)$.

\section{Structural Analysis and Comparison of Flavivirus Epitopes}

Experimentally identified WN virus epitopes were assigned to the crystallographic or cryo-EM structures of the $\mathrm{WN}$ virus $\mathrm{sE}$ protein monomer (PDB 2I69) (25), the Kunjin virus (KUNV) C protein (PDB 1SFK) (36), as well as the Japanese encephalitis (JE) virus E dimers (PDB 3P54 and 5WSN) $(37,38)$ and the St. Louis encephalitis (SLE) virus E trimer (PDB 4FG0) (39), all belonging to the same serocomplex, using PyMol (Schrödinger LLC, https://pymol.org/). For comparisons, all epitopes were derived from ex vivo ELISPOT assays obtained with human $\mathrm{CD} 4 \mathrm{~T}$ cells and peptides that span the entire protein sequences $(22,23,40,41)$. Crystallographic structures used for assignment of experimentally identified epitopes were KUN virus C (PDB 1SFK), Zika sE (5LBV) (26), DEN-2 sE (PDB 1OAN) (27), and YF sE (PDB 6EPK) (28). For comparison of all mosquito-borne flavivirus protein sequences and epitopes of $\mathrm{C}$ and $\mathrm{E}$, multiple sequence alignments were performed (GenBank: Zika virus KJ776791; DEN 1-4 viruses AF226687, M29095, DQ863638, GQ398256; YF virus CAA27332; WN virus DQ211652 and JE virus D90194) using Clustal Omega and manually refined, as described previously (42-44). This analysis also included predicted MHC II-binding peptides derived from DEN virus C or $\mathrm{E}$ that were positive in at least two responders $(45,46)$, as well as epitopes from the JE virus $C$ and $E$ proteins (47).

Structural similarity of the identified epitope regions was assessed using crystallographic structures of the $\mathrm{WN}$ virus (PDB 2I69), YF virus (PDB 6EPK), Zika virus (PDB 5LBV), and DEN virus $\mathrm{SE}$ proteins (PDB 1OAN) lacking the stem-anchor region. For selected WN virus epitope regions E41, E149, E245, and
E381, as well as for the corresponding regions in YF, Zika, and DEN viruses, structural superposition of $\mathrm{WN}$ virus $\mathrm{sE}$ domains I (E41, E149), II (E245), or III (E381), respectively onto those of YF, Zika and DEN viruses was performed using the PyMOL algorithms "align" and "super" (48, 49). Rootmean-square deviation (RMSD) of selected epitope regions was computed through the PyMOL "rms_cur" command (without further fitting).

\section{HLA Genotyping}

HLA-DRB1, HLA-DQA1, HLA-DQB1, HLA-DPA1, and HLADPB1 alleles from all study participants were genotyped by sequencing of the whole gene. Genotyping of HLA-DRB3/4/5 allele genotyping was done from exon 2 to the $3^{\prime}$ UTR by next generation sequencing as described previously $(22,50)$. Briefly, long-range PCR products were generated by allele-specific primers and libraries generated by enzymatic fragmentation of the amplicons. After ligation to barcoded adapters the libraries were subjected to an emulsion PCR and the product sequenced on an Ion Torrent sequencing device (IonTorrent PGM, Thermo Fisher Scientific Inc., Waltham, MA). Sequences were analyzed using HLATypeStream (Thermo Fisher Scientific Inc., Waltham, $\mathrm{MA}$ ) and NGS GenDX (GenDX, Utrecht, NL) software. HLA genotypes were assigned on basis of the IMGT/HLA database. For HLA-DQ predictions, haplotype compositions of -DQA1 and $-\mathrm{DQB1}$ were assigned, based on the strongest linkage between these alleles, according to the reference HLA haplotype frequency standards (51).

\section{In silico Prediction of MHC II Binding}

Predictions were done in July 2019 using the Immune Epitope Database (IEDB) analysis tools "IEDB recommended" (www. iedb.org) and "NetMHCIIpan" (52, 53). C and E protein sequences of WN virus (protein accession code: AGX89731) were entered separately. Predictions were done for all experimentally tested peptides and the HLA class II alleles from all individuals (Table S2). For individual predictions, query submission was automated using the framework provided by the PeptX project (54).

\section{Data Analysis}

Statistical analyses were performed with GraphPad Prism, version 5. Comparisons of overall $\mathrm{CD} 4 \mathrm{~T}$ cell reactivity in asymptomatic donors and WND patients was done using a non-parametric Kruskal-Wallis test. A Wilcoxon-signed rank test was used for comparison of the number of peptides that induced a response in asymptomatic donors and WND patients. A Spearman correlation coefficient was calculated for evaluation of two-by-two correlations. The strength of associations between expression of a specific allele and detection of a positive epitope response was calculated as described previously $(55,56)$. Briefly, odds ratios (ORs) were calculated, according to the following formula: $O R=\frac{(A+R+) x(A-R-)}{(A-R+) x(A+R-)}$.

$A+R+=$ number of subjects who expressed the specific allele and had a positive response to the specific peptide, $A+R-=$ number of subjects who expressed the specific allele but did not have a positive response to the specific peptide, $A-R+=$ number of subjects who did not express the specific allele but 
had a positive response to the specific peptide, $A-R-=$ number of subjects who did not express the specific allele and did not have a positive response to the specific peptide (56). Fisher's exact test was applied to calculate the statistical significance of the association between one or more specific HLA alleles and the response to a specific peptide (55). A $p$-value $<0.05$ was considered statistically significant.

\section{RESULTS}

\section{CD4 T Cell Response Against WN Virus Structural Proteins}

We first investigated the overall reactivity of $\mathrm{CD} 4 \mathrm{~T}$ cell responses to peptides derived from the $\mathrm{WN}$ virus structural proteins, the capsid C, membrane prM/M and envelope E (Figure 1A). PBMC samples from $\mathrm{WN}$ virus-infected individuals were depleted of CD8-positive cells and tested in IL-2 ELISPOT assays with pools of overlapping 15 mer peptides that cover the entire sequence of each of the structural proteins. The study population consisted of 29 subjects (18 asymptomatic/11 WND patients; age range 2770 years) (Table 1), recruited at a mean of $40 \pm 6$ days after diagnosis. In terms of the overall magnitude, highest responses were elicited by E peptides, which accounted for $57 \%$ of the total response, followed by $\mathrm{C}$ and prM peptides, which accounted for 29 and $14 \%$ of the total response, respectively (Figures 1B,C). In contrast, none of the flavivirus-naïve individuals showed a response to any of the $\mathrm{C}$, prM and $\mathrm{E}$ peptides, confirming the specificity of this assay (Figure 1B).

To determine the epitope specificities of responses, we performed IL-2 ELISPOT assays using peptide matrix pools and single peptides covering the entire $\mathrm{C}$ and $\mathrm{E}$ proteins. As observed for other flaviviruses (22-24), the prM peptides yielded only weak positive signals (Figure 1B), and therefore single peptide analysis was not performed. On average, individual responses were directed against five CD4 $\mathrm{T}$ cell epitopes accounting for a median 148 spot forming cells (SFCs) (range, 31-414 SFCs). There were no significant differences in the breadth or magnitude of responses between WND patients (median, 6.0 epitopes; 205 SFCs, range: 88-414) and asymptomatic subjects (median, 3.5 epitopes, 94.5 SFCs, range: $31-412$ ). The cumulative number of spots for each peptide, using the results from all subjects obtained with the single-peptide testing, is displayed in Figure 2A. Individuals with asymptomatic infection and WND yielded similar epitope response patterns $(p<0.0001$, Spearman correlation $r=2.8$ ) (Figure S1). Overall, we identified 61 peptides that induced a CD4 $\mathrm{T}$ cell response, indicating a substantial heterogeneity in the individual epitope reactivities (Table S1). However, closer inspection of the data showed that few epitopes accounted for the majority of the response. These epitopes, recognized in two or more individuals, accounted for $50 \%$ of the total SFC responses and were defined as immunodominant. The immunodominant peptides clustered in two antigenic regions of $\mathrm{C}(\mathrm{C} 41$ and $\mathrm{C} 73)$ and in eight regions of E (E41, E125, E149, E205, E245, E325, E381, and E417) (Figure 2A).

\section{Structural Analysis of Immunodominant Sites in C and E Proteins}

Since the structural context of an epitope has been proposed to influence immunodominance $(15-19,57,58)$, we next analyzed the structural characteristics of the protein regions from which the identified epitopes were derived. For this purpose, we mapped the immunodominant epitopes on the three-dimensional structures of the $\mathrm{WN}$ virus $\mathrm{C}$ and $\mathrm{E}$ proteins. As illustrated in Figure 2B, responses to the $\mathrm{C}$ protein were mainly focused to helices $\mathrm{H} 2$ and $\mathrm{H} 4$, whereas helices $\mathrm{H} 1, \mathrm{H} 3$, and the $\mathrm{N}$-terminal part of $\mathrm{C}$ did not elicit dominant responses. In the E protein (Figure 2C), immunodominant epitopes clustered in each of the three domains [three in domain I (E41, E125, and E149), two in domain II (E205 and E245), two in domain III (E325, E381)] and in the stem region (E417). As shown in Figures 2D,E, epitopes from all three domains were located at the outside of the $\mathrm{E}$ protein in its dimeric conformation as well as in its trimeric form. In addition, the trimer exposes an epitope (E417) in the stem region (Figure 2E), whereas the stem is hidden below the $\mathrm{E}$ ectodomain in its pre-fusion conformation (Figures 1A, 2D).

We next compared the experimentally identified $\mathrm{WN}$ virus epitopes with the epitopes previously determined for other mosquito-borne flaviviruses, including YF, Zika, and DEN viruses. All of these epitopes were identified in ex vivo ELISPOT testing of human CD4 $\mathrm{T}$ cells and overlapping peptides covering the entire protein sequences $(22,23,40,41)$. As can be seen in Figure 3A, immunodominant regions in $\mathrm{C}$ were uniformly located at positions in helices $\mathrm{H} 2$ and $\mathrm{H} 4$ (C41, C73). In E (Figure 3B), three of the dominant $\mathrm{WN}$ virus epitopes (E41, E245, and E381) mapped to sites harboring immunodominant epitopes in all mosquito-borne flaviviruses, except for E381, which was not identified in DEN virus infections. Structurally, these common epitope regions encompassed $B$-sheets as well as loops that are about 20 amino acids long and are devoid of disulphide bridges (Figure 3B). In addition, we identified two dominant sites (E125 and E205) that were congruent between WN, Zika, and DEN viruses. These data together with all epitopes identified by ex vivo ELISPOT assays are shown in Figure S2. Two WN virus epitopes (E325 and E417) were not present in DEN, Zika, and YF viruses, but overlapped with those previously identified in Japanese encephalitis virus, a closely related flavivirus of the same serocomplex (Figure S2). In contrast, one epitope, E149, which involves an extra $\alpha$-helix in DI, was only found in WN virus (Figure S2).

As a further estimate for the structural homology of the common flavivirus epitope sites, we computed the RMSD of selected epitope regions after pairwise structural alignments of $\mathrm{WN}$ virus $\mathrm{sE}$ protein domains with those of YF, Zika and DEN viruses, respectively. The analysis included epitope regions E41, E245, and E381, which were common among flaviviruses (Figure 3B), as well as epitope E149, which had no equivalent in other flaviviruses (Figure S2). As can be seen in Figure 4, alignment of sE proteins yielded RMSD values of 2.58$3.96 \AA$, consistent with those for homologous proteins $(48,59)$. The $B$-sheet encompassing E41 yielded very low RMSD values 


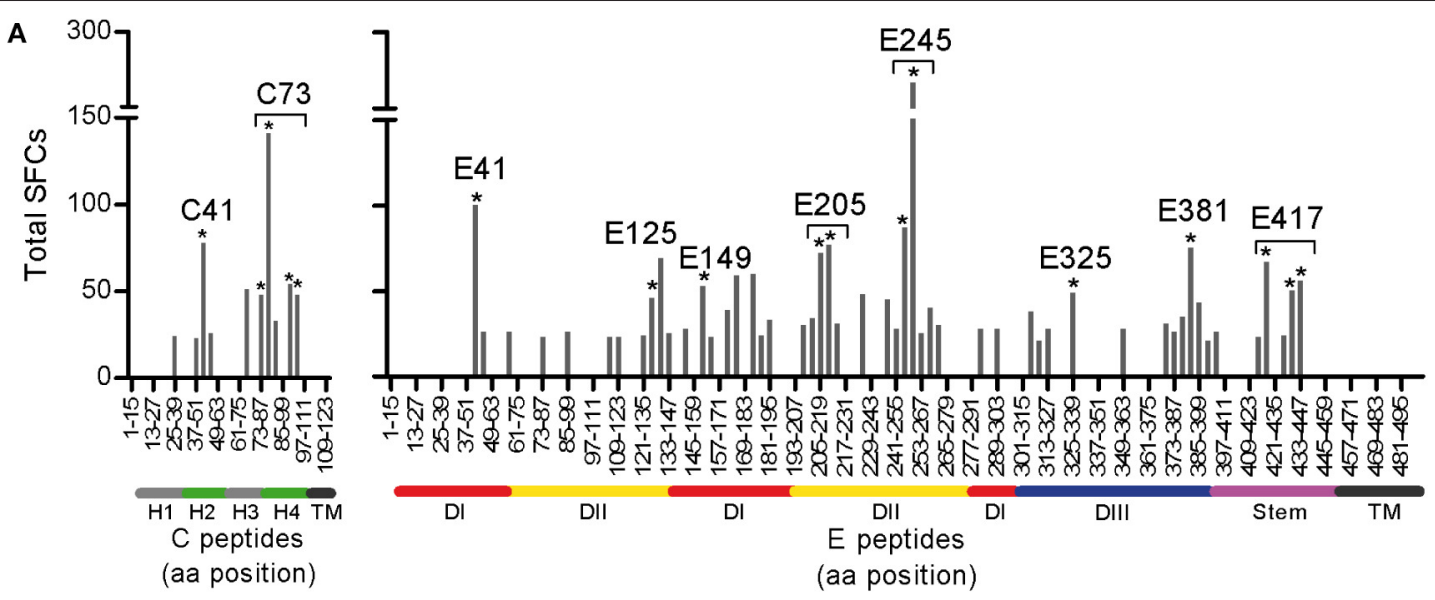

B

C
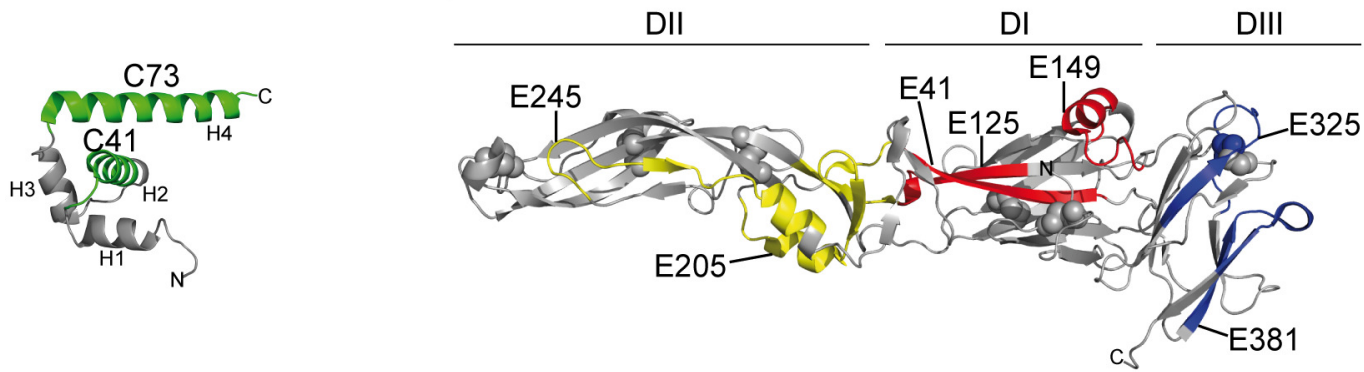

D

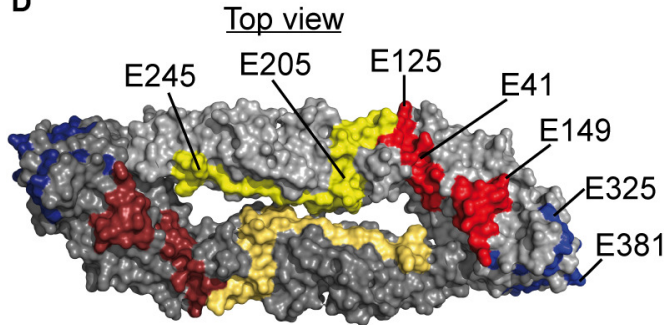

Side view

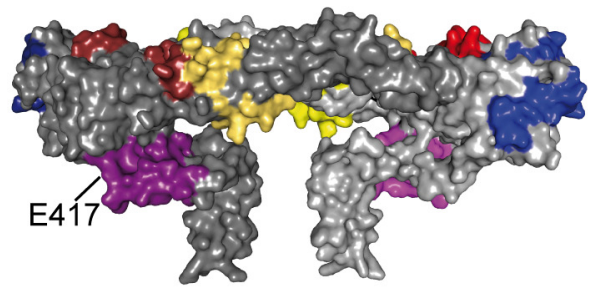

E

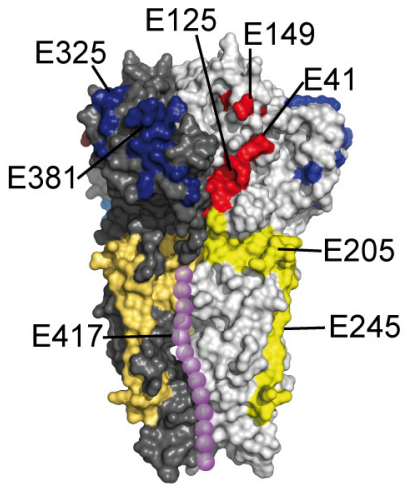

FIGURE 2 | Mapping of CD4 T Cell Epitopes to WN Virus C and E Proteins. (A) Total spot counts of positive responses to single peptides. Amino acid positions of peptides in $\mathrm{C}$ and $\mathrm{E}$ protein sequences are indicated on the $\mathrm{x}$-axes. Peptides recognized in two or more individuals are indicated by asterisks and are designated by the first amino acid of the 15 mer peptide. (B) Ribbon diagram of the WN virus lineage 1 variant Kunjin $\mathrm{C}$ protein (PDB 1SFK) (36), comprising four helices (H1-H4). (C) Ribbon representation of the WN virus soluble E (sE) ectodomain (PDB 2I69; side view) (25), consisting of three domains (DI-DIII). (D) Surface representation of the Japanese encephalitis virus pre-fusion sE dimer (top view, PDB 3P54) (37) and the full-length E dimer (side view, PDB 5WSN) (38). (E) Surface depiction of the St. Louis encephalitis virus post-fusion E protein trimer (PDB 4FG0; side view) (39); the unresolved stem is added schematically to the structure and shown as dotted line along domain II (purple). Immunodominant WN virus peptides are colored as follows: C, green; E, DI-red, DIl-yellow, DIII-blue, and stem-purple.

(0.90-1.61 $\AA$ ), and values below $2 \AA$ were also observed for all pairwise comparisons of E245 and E381, except for E245 in DEN virus, which had a value of 3.50 to $3.59 \AA$. In contrast, E149 yielded RMSD values of 6.74 to $26.10 \AA$, indicating a structurally divergent region. In fact, in $\mathrm{WN}$ virus, this site harbors an extra $\alpha$-helix protruding from the upper part of E DI, which is absent 


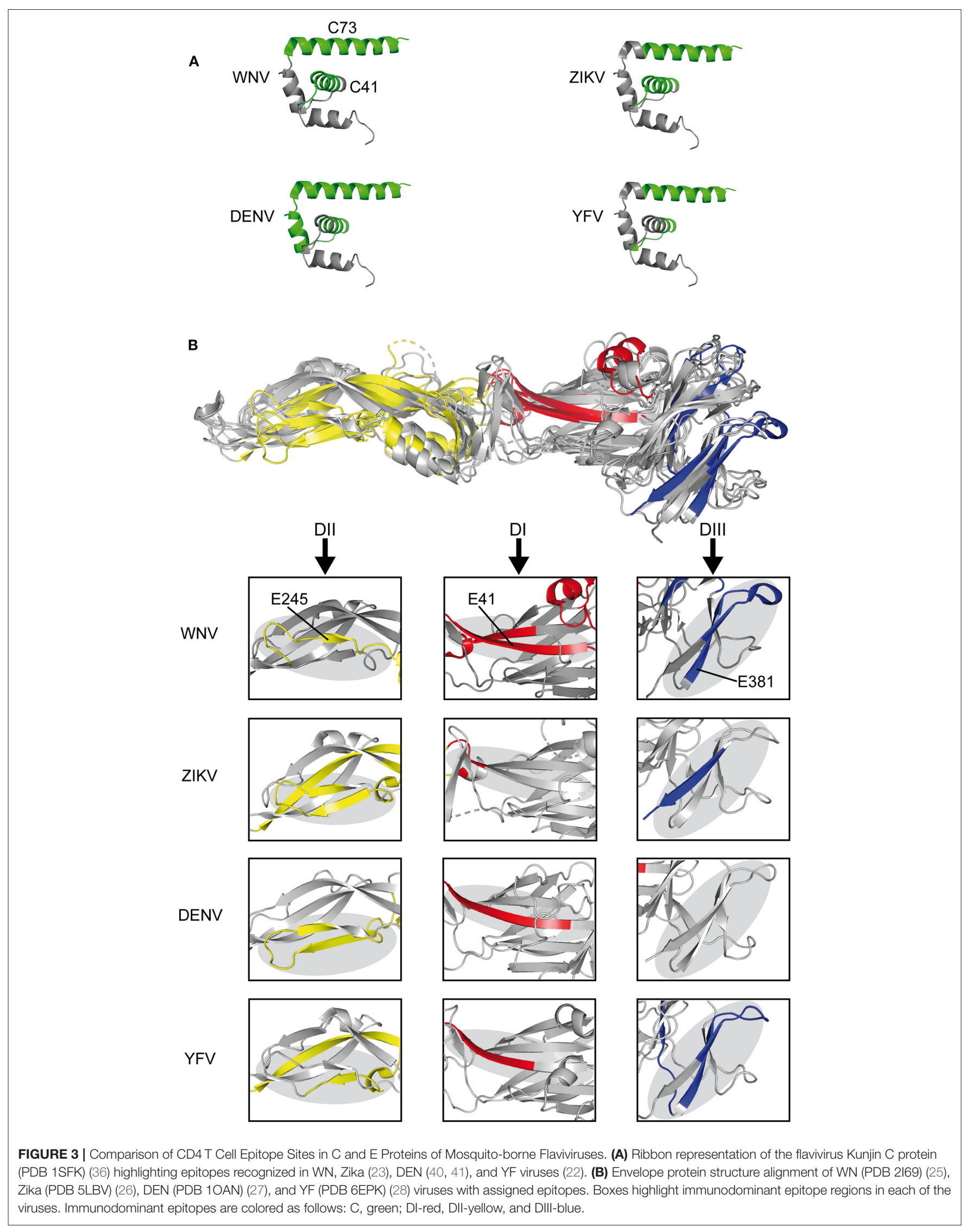




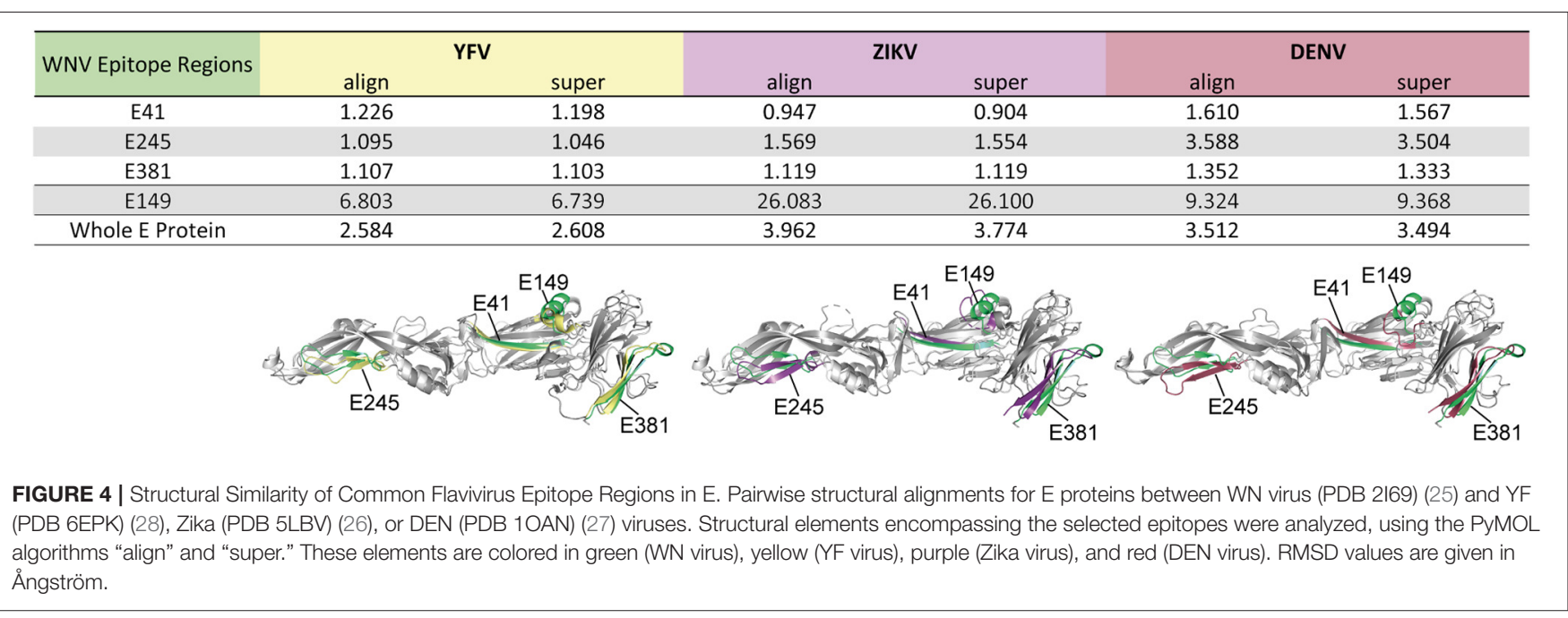

in Zika and DEN viruses (Figure 4). It is notable that an $\alpha$-helix occurs at a similar sequence position in the YF virus $\mathrm{E}$ protein, however this helix exhibits a $\sim 90^{\circ}$ twisted orientation and sticks closer to the surface of E DI (Figure 4). Together, the data suggest that the common epitope sites resulted from conserved structural features that favor their selection across different flaviviruses.

\section{HLA II Binding Prediction and Association of Epitope Responses}

The immunogenicity of CD4 T cell epitopes is also determined by the affinity of a particular peptide to an individual's HLA repertoire. As a prerequisite for MHC II affinity prediction, HLA genotyping of class II alleles (DRB1, DRB3, DRB4, DRB5, DQA1, DQB1, DPA1, and DPB1) was performed for each of the 29 donors (Table S2). First, HLA binding affinity was predicted for the entire set of experimentally tested $\mathrm{WN}$ virus $\mathrm{C}$ and $\mathrm{E}$ peptides $(n=150)$ using the NetMHCIIpan algorithm provided by the Immune Epitope Database (IEDB). Approximately 1,400 peptide-MHC II pairs yielded IC $_{50}$ values of $<500 \mathrm{nM}$, indicating likely binders $(52,53)$. Analysis of the data displayed in Figure 5A revealed that $97 \%$ of the peptides were predicted with several different HLA alleles (up to 30 different alleles/peptide), and only $3 \%$ were predicted exclusively for one or no allele. We therefore conclude that the majority of peptides derived from $\mathrm{C}$ and $\mathrm{E}$ proteins could theoretically be presented by a large number of different MHC molecules expressed in this study cohort. However, a considerable number of frequently predicted peptides did not elicit a dominant CD4 T cell response in ELISPOT assays. This was especially the case for peptides derived from the transmembrane anchors (aa 449-501), as well as for peptides from domains II (aa 261-295) and III (aa 349-375) (Figure 5A). These findings are consistent with the notion that HLA binding is a necessary but not sufficient requirement for $\mathrm{T}$ cell responses $(61,62)$.

In addition to this population-based approach, we assessed specifically for each individual which of the HLA alleles had the best prediction value (best percentile rank) for the peptides detected in ELISPOT assays, using the Immune Epitope Database
(IEDB) analysis tool "IEDB recommended" (www.iedb.org). In this analysis, $82 \%$ of all experimentally identified peptides had an IEDB percentile rank of $\leq 20$ for the individual HLA II alleles. For the illustration of the results in Figure 5B, a chord diagram was used which presents all experimentally identified epitopes on the left side of the circle, connected to the HLA II alleles predicted with best percentile ranks on the right side of the circle. Notably, more than $50 \%$ of the immunodominant peptides were predicted to bind quite strongly, with percentile ranks $<1.5$, and $90 \%$ with percentile ranks $<10$ (Table S3). These data indicate that most of the immunodominant epitopes were predicted as strong binders.

To assess the strength of association between a particular HLA allele and the epitope response in each individual, we calculated odds ratios (ORs) for all combinations of HLA alleles and dominant peptides shown in Figure 5B. In the case of peptides predicted as binders for more than one HLA allele, combined calculations for these alleles were performed, as described previously (55). Evidence for significant associations with specific HLA alleles were obtained for most but not all immunodominant peptides (Table $\mathbf{S 3}$ and Figure 5C). The data show that, while only $25 \%(3 / 12)$ of these epitopes were associated with one single HLA allele (C41-DRB4*01:03, C73DRB5 $^{*} 01: 01$ and E381-DRB1*11:01), 75\% (9/12) were associated with two to four different HLA molecules (Figure 5C). These findings indicate that most immunodominant $\mathrm{WN}$ virus epitopes are recognized in the context of different HLA molecules, consistent with the well-known phenomenon of promiscuous binding of immunogenic peptides $(63,64)$. The data also corroborate previous results obtained with tetramers using different HLA-DR molecules (60) which match almost half of the $\mathrm{C}$ and $\mathrm{E}$ peptides identified in the present study (peptide matches are underlined in Figure 5C). The OR calculations were also applied to asymptomatic or WND subjects separately. Three of the epitopes yielded a significant HLA association in asymptomatic donors but not in WND patients. These epitopes (E41-IDVKMMNMEAANLAD-HLADRB1*01:02 and -DRB1*04:01 [ $p=0.039$; OR 29.0], E381DSYIVVGRGEQQINH-HLA-DRB $1^{*} 11: 01 \quad[p=0.0196$; OR 


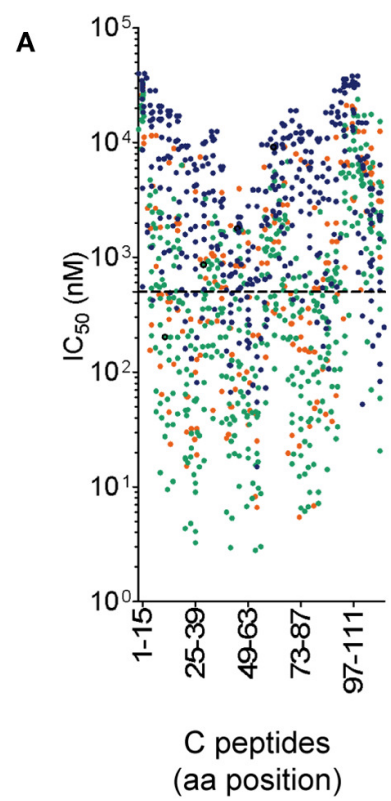

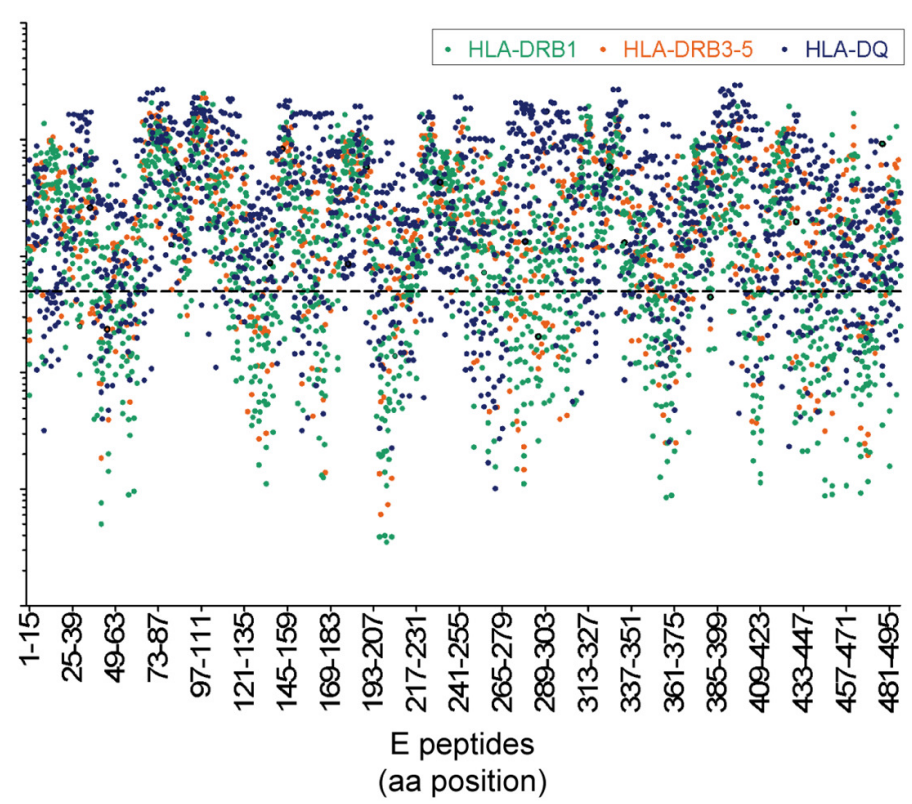

(aa position)
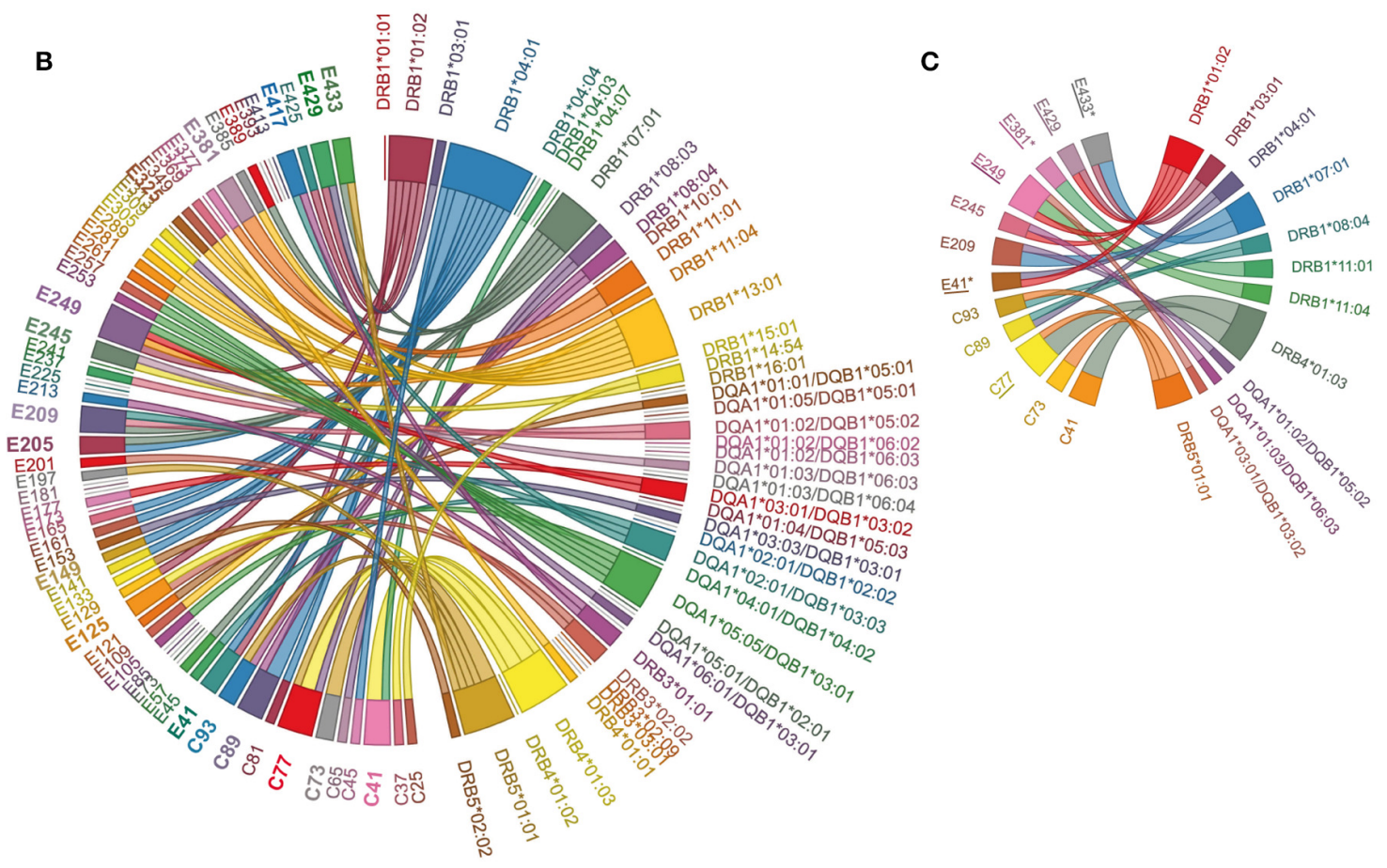

FIGURE 5 | Peptide-MHC II Binding Prediction and HLA Association of West Nile Virus Epitopes. (A) Predicted IC 50 values for experimentally tested peptides and the HLA II alleles of the study cohort. Peptides with the highest affinities locate toward the bottom of the $\mathrm{y}$-axes and have $\mathrm{IC}_{50}$ values below $500 \mathrm{nM}$ (dotted line). (B) The chord diagram demonstrates for each individual, the experimentally identified epitope on the left side of the circle, connected with the HLA II allele predicted with best percentile rank on the right side of the circle. Immunodominant peptides are in bold. (C) Chord diagram indicating HLA II alleles associated with immunodominant epitopes in $\mathrm{C}$ and $\mathrm{E}$. Epitopes detected only in asymptomatic individuals are indicated by asterisks. Epitope sequences previously identified by HLA II tetramer staining (60) are underlined. 
51.7] and E433-GVFTSVGKAIHQVFG-HLA-DRB1*07:01 [ $p$ $=0.039$; OR 29.0]) were detected experimentally only in asymptomatic but in none of the WND subjects and are indicated by asterisks in Figure 5C.

\section{DISCUSSION}

Factors responsible for controlling the immunodominance of certain epitope sites of viral proteins in CD4 $\mathrm{T}$ cell responses are poorly defined but can be of great importance for generating protective immunity. A better understanding of these fundamentals requires unbiased exploration of the ex vivo $\mathrm{T}$ cell epitope repertoire, defining the structural features and the host genetic factors that underlie the preferential selection of epitopes. Toward these objectives, we examined the CD4 T cell epitope specificities in $29 \mathrm{WN}$ virus-infected individuals, using a library of overlapping peptides covering the entire virion proteins. We focused on CD4 T cells directed against epitopes within the virus structural proteins, because these can mediate help to B cells by direct cell-cell interactions and are therefore essential for the production of neutralizing antibodies, the major protective correlate in flavivirus infections (6-8).

Our study demonstrates that dominant CD4 T helper cell responses are directed to two helices in the virus capsid and to surface-exposed regions of the viral envelope protein $\mathrm{E}$ in its pre- and post-fusion forms. This immunodominance pattern was strikingly similar to those previously identified for distantly related flaviviruses, including Zika (23), DEN (40, 41), and YF (22) viruses. Especially with epitopes of the capsid protein, the immunodominance patterns were remarkably similar for each of the different flaviviruses. Also in the case of E, we observed a strong overlap of specific epitope regions, particularly with respect to three epitope sites (E41, E245, and E381) that were almost uniformly present in the flaviviruses examined. In our study, epitope reactivities of WN virus-specific CD4 T cells were determined in an ex vivo ELISPOT assay using IL-2 that has been applied in a number of previous studies investigating flavivirusspecific CD4 T cell responses $(22-24,65)$. It was shown that most of the peptide-specific CD4 T cells are polyfunctional (e.g., triple- $\left[\mathrm{IL}-2^{+}\right.$TNF- $\alpha^{+}$IFN- $\left.\gamma^{+}\right]$or dual-positive $\left[\mathrm{IL}-2^{+} \mathrm{IFN}-\gamma^{+}\right]$) cells with at least as many CD4 T cells secreting IL-2 as compared to IFN- $\gamma$ (65). Consistent with these findings, the present analysis revealed similar distributions of epitopes that were identified using IL-2 $(22,23)$ or IFN- $\gamma$ ELISPOT assays $(40,41)$. However, we cannot exclude that our approach could miss epitopes targeted by single IFN- $\gamma$ positive cells. Further studies that involve dual IFN- $\gamma$ and IL-2 ELISPOT testing will be required to address this issue.

Analyses in the context of the atomic structures of the corresponding E proteins showed that the common epitopes are displayed in structurally conserved elements and preferentially locate to surface-exposed regions of E (e.g., the domain I-II hinge regions [E41 and E125] as well as the lateral ridge of domain III [E325 and E381]) which have been shown to be important sites for potent neutralizing antibodies against $\mathrm{WN}$ virus in humans $(33,66,67)$. Our findings are consistent with previous studies demonstrating that CD4 T cell epitopes are preferentially located at exposed protein sites or at flanks of conformationally flexible loops $(15-19,68,69)$. Such segments may offer initial cleavage sites for proteolytic processing and are easily accessible binding sites for MHC II molecules $(14,70)$. Interestingly, the only immunodominant WN virus epitope (E149) that had no overlap with epitopes from other flaviviruses, included an $\alpha$ helix that is absent from Zika and DEN viruses. Its protrusion from the upper part of DI may increase its accessibility for proteolytic processing and/or MHC binding. Further evidence for the structural influence on epitope selection was obtained by our finding that several peptides predicted to bind a considerable number of HLA molecules were not observed experimentally. This is especially true for peptides from the transmembrane region that are shielded in the lipid bilayer, which might impose strong constraints on peptide generation (24).

In contrast to the other WN virus epitopes identified, the E417 epitope appears to be less accessible in the context of mature virions, because it is sandwiched between the external protein shell and the lipid membrane (Figure 1A). However, upon endocytosis and encounter of the acidic $\mathrm{pH}$ in the endosome, flavivirus E proteins undergo a fusogenic conformational change from dimers to trimers, in which the stem is located at the outside $(12,13)$. Since fusion can already occur at the $\mathrm{pH}$ of early endosomes (71), the post-fusion conformation may be an important substrate for generating peptides of the stem region. Such structural aspects may also explain previous observations with TBE virus, which demonstrated that epitopes derived from the stem are immunodominant only in naturally infected patients but not in those vaccinated with a formalin-inactivated vaccine, in which the prefusion conformation of $\mathrm{E}$ is stabilized by formaldehyde cross-linking (24). There are many other wellknown examples, such as influenza virus or HIV, which undergo conformational changes that may play a role in the preferential selection of certain epitopes. Moreover, studies with influenza virus reported that some peptides are generated only during protein synthesis in infected cells but not upon exogenous uptake of the same antigen $(20,72)$.

In addition to protein structure-specific factors that are responsible for characteristic immunodominance patterns, our ELISPOT data revealed considerable individual variation in epitope specificities, indicating additional influences of individual-specific factors that control epitope recognition. Evaluations based on in silico predicted peptide-MHC II affinities provide evidence that most immunodominant peptides were predicted as strong binders and could potentially be presented in combination with multiple different MHC II molecules. Our results are consistent with recent studies (60), demonstrating that CD4 T cells could be detected in direct ex vivo samples by peptide-matched tetramers, which included a number of different alleles. Comparing the characteristics of $\mathrm{WN}$ virus-specific CD4 $\mathrm{T}$ cells in individuals with either neuroinvasive disease or asymptomatic infection, the same study found that individuals with neuroinvasive disease had higher numbers of virus-specific CD4T cells (60). This is consistent with the finding that the only patient in our study with neuroinvasive disease (patient \#519) demonstrated a substantially higher magnitude of response than other patients, which could be an effect of increased viral replication and/or delayed viral clearance, as described in a significant percentage 
of patients with WN virus encephalitis (73). Apart from this single case and in line with previous findings (74), we observed no differences with respect to the overall magnitude of response between individuals with WND or asymptomatic infection, and no difference was apparent in the breadth of responses among these groups.

Despite the overall similarities of epitope responses between asymptomatic subjects and WND patients, we did observe certain peptide-HLA combinations which only occurred in asymptomatic individuals. It is unclear at present whether these differences relate to the presence of alleles that protect from WND. An HLA-specific association for both protection and susceptibility to WND was suggested in previous studies (75-77). Additional research is needed to clarify whether such differences could discriminate patients with different disease outcomes. Knowledge of the immunodominant epitopes displayed by such alleles could substantially contribute to our understanding of the determinants that impact the clinical outcome of infection and the efficacy of vaccines.

In summary, we have demonstrated that $\mathrm{WN}$ virus infection elicits CD4 T cell responses to peptides that cluster in specific regions of the viral structural proteins and are frequently predicted as strong binders for individual HLA alleles. The immunodominant epitopes locate to structurally conserved antigen regions which are also frequently targeted in other clinically relevant flaviviruses, including yellow fever, dengue and Zika viruses. Together, these data provide novel insights into a key aspect of flavivirus immunity, namely how virion protein structure shapes $\mathrm{CD} 4 \mathrm{~T}$ cell responses, which is an important issue to consider in rational vaccine design.

\section{DATA AVAILABILITY STATEMENT}

All datasets generated for this study are included in the article/Supplementary Material.

\section{REFERENCES}

1. Kaiser JA, Barrett ADT. Twenty years of progress toward west nile virus vaccine development. Viruses. (2019) 11:E823. doi: 10.3390/v11090823

2. Aberle SW, Kolodziejek J, Jungbauer C, Stiasny K, Aberle JH, Zoufaly A, et al. Increase in human West Nile and Usutu virus infections, Austria, 2018. Eurosurveillance. (2018) 23:7-12. doi: 10.2807/1560-7917.ES.2018.23.43.1800545

3. Barrett ADT. West Nile in Europe: an increasing public health problem. $J$ Travel Med. (2018) 25:1-2. doi: 10.1093/jtm/tay096

4. Gould LH, Fikrig E. West Nile virus: a growing concern? J Clin Invest. (2004) 113:1102-7. doi: 10.1172/JCI21623

5. West Nile Virus-Symptoms, Diagnosis and Treatment. Available online at: https://www.cdc.gov/westnile/symptoms/index.html (accessed October 8, 2019).

6. Diamond MS, Pierson TC, Fremont DH. The structural immunology of antibody protection against West Nile virus. Immunol Rev. (2008) 225:212-25. doi: 10.1111/j.1600-065X.2008.00676.x

7. Mehlhop E, Diamond MS. The molecular basis of antibody protection against West Nile Virus. Hum Antibody Therapeut Viral Disease. (2008) 317:125-53. doi: 10.1007/978-3-540-72146-8_5

8. Pierson TC, Fremont DH, Kuhn RJ, Diamond MS. Structural insights into the mechanisms of antibody-mediated neutralization of flavivirus infection:

\section{ETHICS STATEMENT}

The studies involving human participants were reviewed and approved by the Ethics committee of the Medical University of Vienna, Austria. The patients/participants provided their written informed consent to participate in this study.

\section{AUTHOR CONTRIBUTIONS}

MK, JA, FH, SA, KS, and SM performed experiments, reviewed data, and planned experimental strategy. BK, MK, FS, and DF performed bioinformatic analysis. GF and IF performed and coordinated HLA typing. FB, IC, HL, and CJ collected samples and provided clinical information. JA and $\mathrm{FH}$ conceived the study. JA wrote the first draft. FH and MK contributed to the writing of the manuscript. All authors critically read and edited the manuscript.

\section{FUNDING}

This study was funded by research grants from the Austrian Science Fund FWF (JA: P29881-B30; KS: P29928-B30).

\section{ACKNOWLEDGMENTS}

We thank Jutta Hutecek, Silvia Schwödiauer, Ursula Sinzinger, and Walter Holzer for excellent technical assistance. We thank Michael S. Diamond for providing the monoclonal antibody E16.

\section{SUPPLEMENTARY MATERIAL}

The Supplementary Material for this article can be found online at: https://www.frontiersin.org/articles/10.3389/fimmu. 2020.00016/full\#supplementary-material

implications for vaccine development. Cell Host Microbe. (2008) 4:229-38. doi: 10.1016/j.chom.2008.08.004

9. Brien JD, Uhrlaub JL, Nikolich-Zugich J. West Nile virus-specific CD4 T cells exhibit direct antiviral cytokine secretion and cytotoxicity and are sufficient for antiviral protection. J Immunol. (2008) 181:8568-75. doi: 10.4049/jimmunol.181.12.8568

10. Sitati EM, Diamond MS. CD4(+) T-cell responses are required for clearance of West Nile virus from the central nervous system. J Virol. (2006) 80:12060-9. doi: 10.1128/JVI.01650-06

11. Stadler K, Allison SL, Schalich J, Heinz FX. Proteolytic activation of tick-borne encephalitis virus by furin. J Virol. (1997) 71:8475-81. doi: 10.1128/JVI.71.11.8475-8481.1997

12. Harrison SC. Viral membrane fusion. Virology. (2015) 479-80:498-507. doi: 10.1016/j.virol.2015.03.043

13. Stiasny K, Fritz R, Pangerl K, Heinz FX. Molecular mechanisms of flavivirus membrane fusion. Amino Acids. (2011) 41:1159-63. doi: 10.1007/s00726-009-0370-4

14. Kim A, Sadegh-Nasseri S. Determinants of immunodominance for CD4 T cells. Curr Opin Immunol. (2015) 34:9-15. doi: 10.1016/j.coi.2014.12.005

15. Dai GX, Steede NK, Landry SJ. Allocation of helper T-cell epitope immunodominance according to three-dimensional structure in the human immunodeficiency virus type I envelope glycoprotein gp120. J Biol Chem. (2001) 276:41913-20. doi: 10.1074/jbc.M106018200 
16. Landry SJ, Moss DL, Cui D, Ferrie RP, Fullerton ML, Wells EA, et al. Structural basis for CD4+ $\mathrm{T}$ cell epitope dominance in arbo-flavivirus envelope proteins: a meta-analysis. Viral Immunol. (2017) 30:479-89. doi: $10.1089 /$ vim. 2017.0008

17. Landry SJ. Three-dimensional structure determines the pattern of CD4(+) T-cell epitope dominance in influenza virus hemagglutinin. J Virol. (2008) 82:1238-48. doi: 10.1128/JVI.02026-07

18. Mirano-Bascos D, Tary-Lehmann M, Landry SJ. Antigen structure influences helper T-cell epitope dominance in the human immune response to HIV envelope glycoprotein gp120. European J Immunol. (2008) 38:1231-7. doi: 10.1002/eji.200738011

19. Carmicle S, Steede NK, Landry SJ. Antigen three-dimensional structure guides the processing and presentation of helper T-cell epitopes. Mol Immunol. (2007) 44:1159-68. doi: 10.1016/j.molimm.2006.06.014

20. Eisenlohr LC, Luckashenak N, Apcher S, Miller MA, Sinnathamby G. Beyond the classical: influenza virus and the elucidation of alternative MHC class II-restricted antigen processing pathways. Immunol Res. (2011) 51:237-48. doi: 10.1007/s12026-011-8257-3

21. Aberle JH, Koblischke M, Stiasny K. CD4 T cell responses to flaviviruses. J Clin Virol. (2018) 108:126-31. doi: 10.1016/j.jcv.2018.09.020

22. Koblischke M, Mackroth MS, Schwaiger J, Fae I, Fischer G, Stiasny $\mathrm{K}$, et al. Protein structure shapes immunodominance in the CD4T cell response to yellow fever vaccination. Sci Rep. (2017) 7:8907. doi: 10.1038/s41598-017-09331-w

23. Koblischke M, Stiasny K, Aberle SW, Malafa S, Tsouchnikas G, Schwaiger $\mathrm{J}$, et al. Structural influence on the dominance of virus-specific CD4 T cell epitopes in Zika virus infection. Front Immunol. (2018) 9:2083. doi: 10.3389/fimmu.2018.02083

24. Schwaiger J, Aberle JH, Stiasny K, Knapp B, Schreiner W, Fae I, et al. Specificities of human CD4(+) T Cell Responses to an Inactivated Flavivirus Vaccine and Infection: correlation with Structure and Epitope Prediction. J Virol. (2014) 88:7828-42. doi: 10.1128/JVI.00196-14

25. Kanai R, Kar K, Anthony K, Gould LH, Ledizet M, Fikrig E, et al. Crystal structure of West Nile virus envelope glycoprotein reveals viral surface epitopes. J Virol. (2006) 80:11000-8. doi: 10.1128/JVI.01735-06

26. Barba-Spaeth G, Dejnirattisai W, Rouvinski A, Vaney MC, Edits IM, Sharma A, et al. Structural basis of potent Zika-dengue virus antibody crossneutralization. Nature. (2016) 539:314. doi: 10.1038/nature19780

27. Modis Y, Ogata S, Clements D, Harrison SC. A ligand-binding pocket in the dengue virus envelope glycoprotein. Proc Natl Acad Sci USA. (2003) 100:6986-91. doi: 10.1073/pnas.0832193100

28. Rey FA, Duquerroy S, Crampon E, Barba-Spaeth G. Crystal Structure of the Precursor Membrane Protein-Envelope Protein Heterodimer From the Yellow Fever Virus. RCSB PDB (2017). Available online at: https://www.rcsb.org/ structure/6EPK.

29. Chen ZM, Ye F, Lin S, Yang FL, Cheng YW, Cao Y, et al. Crystal structure of Usutu virus envelope protein in the pre-fusion state. Virol J. (2018) 15:183. doi: 10.1186/s12985-018-1092-6

30. Rey FA, Heinz FX, Mandl C, Kunz C, Harrison SC. The envelope glycoprotein from tick-borne encephalitis virus at 2 A resolution. Nature. (1995) 375:291-8. doi: 10.1038/375291a0

31. Stiasny K, Aberle SW, Heinz FX. Retrospective identification of human cases of West Nile virus infection in Austria (2009 to 2010) by serological differentiation from Usutu and other flavivirus infections. Eurosurveillance. (2013) 18:26-34. doi: 10.2807/1560-7917.ES2013.18.43. 20614

32. Tang YL, Hapip CA, Liu B, Fang CT. Highly sensitive TaqMan RT-PCR assay for detection and quantification of both lineages of West Nile virus RNA. $J$ Clin Virol. (2006) 36:177-82. doi: 10.1016/j.jcv.2006.02.008

33. Nybakken GE, Oliphant T, Johnson S, Burke S, Diamond MS, Fremont DH. Structural basis of West Nile virus neutralization by a therapeutic antibody. Nature. (2005) 437:764-8. doi: 10.1038/nature03956

34. Stiasny K, Holzmann H, Heinz FX. Characteristics of antibody responses in tick-borne encephalitis vaccination breakthroughs. Vaccine. (2009) 27:7021-6. doi: 10.1016/j.vaccine.2009.09.069

35. Bradt V, Malafa S, von Braun A, Jarmer J, Tsouchnikas G, Medits I, et al. Pre-existing yellow fever immunity impairs and modulates the antibody response to tick-borne encephalitis vaccination. NPJ Vaccines. (2019) 4:38. doi: 10.1038/s41541-019-0133-5

36. Dokland T, Walsh M, Mackenzie JM, Khromykh AA, Ee KH, Wang S. West Nile virus core protein; tetramer structure and ribbon formation. Structure. (2004) 12:1157-63. doi: 10.1016/j.str.2004.04.024

37. Luca VC, AbiMansour J, Nelson CA, Fremont DH. Crystal structure of the Japanese encephalitis virus envelope protein. J Virol. (2012) 86:2337-46. doi: 10.1128/JVI.06072-11

38. Wang XX, Li SH, Zhu L, Nian QG, Yuan S, Gao Q, et al. Near-atomic structure of Japanese encephalitis virus reveals critical determinants of virulence and stability. Nat Commun. (2017) 8:14. doi: 10.1038/s41467-017-00024-6

39. Luca VC, Nelson CA, Fremont DH. Structure of the St. Louis Encephalitis virus postfusion envelope trimer. J Virol. (2013) 87:818-28. doi: 10.1128/JVI.01950-12

40. Rivino L, Kumaran EAP, Jovanovic V, Nadua K, Teo EW, Pang SW, et al. Differential targeting of viral components by CD4(+) versus CD8(+) $\mathrm{T}$ lymphocytes in dengue virus infection. J Virol. (2013) 87:2693-706. doi: 10.1128/JVI.02675-12

41. Simmons CP, Dong T, Chau NV, Dung NTP, Chau TNB, Thao LTT, et al. Early T-cell responses to dengue virus epitopes in Vietnamese adults with secondary dengue virus infections. J Virol. (2005) 79:5665-75. doi: 10.1128/JVI.79.9.5665-5675.2005

42. Ma LX, Jones CT, Groesch TD, Kuhn RJ, Post CB. Solution structure of dengue virus capsid protein reveals another fold. Proc Natl Acad Sci USA. (2004) 101:3414-9. doi: 10.1073/pnas.0305892101

43. Sievers F, Wilm A, Dineen D, Gibson TJ, Karplus K, Li WZ, et al. Fast, scalable generation of high-quality protein multiple sequence alignments using Clustal Omega. Mol Syst Biol. (2011) 7:539. doi: 10.1038/msb.2011.75

44. Sirohi D, Chen ZG, Sun L, Klose T, Pierson TC, Rossmann MG, et al. The 3.8 angstrom resolution cryo-EM structure of Zika virus. Science. (2016) 352:467-70. doi: 10.1126/science.aaf5316

45. Angelo MA, Grifoni A, O’Rourke PH, Sidney J, Paul S, Peters B, et al. Human $\mathrm{CD} 4(+) \mathrm{T}$ cell responses to an attenuated tetravalent dengue vaccine parallel those induced by natural infection in magnitude, HLA restriction, and antigen specificity. J Virol. (2017) 91:e02147-16. doi: 10.1128/JVI.02147-16

46. Weiskopf D, Angelo MA, Grifoni A, O’Rourke PH, Sidney J, Paul S, et al. HLA-DRB1 alleles are associated with different magnitudes of dengue virus-specific CD4(+) T-cell responses. J Infect Dis. (2016) 214:1117-24. doi: 10.1093/infdis/jiw309

47. Turtle L, Bali T, Buxton G, Chib S, Chan S, Soni M, et al. Human T cell responses to Japanese encephalitis virus in health and disease. J Exp Med. (2016) 213:1331-52. doi: 10.1084/jem.20151517

48. Carugo O, Pongor S. A normalized root-mean-square distance for comparing protein three-dimensional structures. Prot Sci. (2001) 10:1470-3. doi: 10.1110/ps.690101

49. Kufareva I, Abagyan R. Methods of protein structure comparison. Methods Mol Biol. (2012) 857:231-57. doi: 10.1007/978-1-61779-588-6_10

50. Fae I, Wenda S, Grill C, Fischer GF. HLA-B*44:138Q: Evidence for a confined deletion and recombination events in an otherwise unaffected HLAhaplotype. Hla. (2019) 93:89-96. doi: 10.1111/tan.13439

51. Klitz W, Maiers M, Spellman S, Baxter-Lowe LA, Schmeckpeper B, Williams TM, et al. New HLA haplotype frequency reference standards: High-resolution and large sample typing of HLA DR-DQ haplotypes in a sample of European Americans. Tissue Antigens. (2003) 62:296-307. doi: 10.1034/j.1399-0039.2003.00103.x

52. Chaves FA, Lee AH, Nayak JL, Richards KA, Sant AJ. The utility and limitations of current Web-available algorithms to predict peptides recognized by $\mathrm{CD} 4 \mathrm{~T}$ cells in response to pathogen infection. J Immunol. (2012) 188:4235-48. doi: 10.4049/jimmunol.1103640

53. Karosiene E, Rasmussen M, Blicher T, Lund O, Buus S, Nielsen $M$. NetMHCIIpan-3.0, a common pan-specific MHC class II prediction method including all three human MHC class II isotypes, HLADR, HLA-DP and HLA-DQ. Immunogenetics. (2013) 65:711-24. doi: 10.1007/s00251-013-0720-y

54. Knapp B, Giczi V, Ribarics R, Schreiner W. PeptX: Using Genetic Algorithms to optimize peptides for MHC binding. BMC Bioinform. (2011) 12:241. doi: 10.1186/1471-2105-12-241 
55. Paul S, Dillon MBC, Arlehamn CSL, Huang H, Davis MM, McKinney DM, et al. A population response analysis approach to assign class II HLA-epitope restrictions. J Immunol. (2015) 194:6164-76. doi: 10.4049/jimmunol.1403074

56. Paul S, Arlehamn CSL, Schulten V, Westernberg L, Sidney J, Peters B, et al. Experimental validation of the RATE tool for inferring HLA restrictions of T cell epitopes. BMC Immunol. (2017) 18:20. doi: 10.1186/s12865-017-0204-1

57. Mettu RR, Charles T, Landry SJ. CD4+T-cell epitope prediction using antigen processing constraints. J Immunol Methods. (2016) 432:72-81. doi: $10.1016 /$ j.jim.2016.02.013

58. Landry SJ. Helper T-cell epitope immunodominance associated with structurally stable segments of hen egg lysozyme and HIV gp120.J Theor Biol. (2000) 203:189-201. doi: 10.1006/jtbi.1999.1056

59. Chothia C, Lesk AM. The relation between the divergence of sequence and structure in proteins. Embo J. (1986) 5:823-6. doi: 10.1002/j.1460-2075.1986.tb04288.x

60. James EA, Gates TJ, LaFond RE, Yamamoto S, Ni C, Mai D, et al. Neuroinvasive West Nile infection elicits elevated and atypically polarized $\mathrm{t}$ cell responses that promote a pathogenic outcome. PLoS Pathogens. (2016) 12:e1005375. doi: 10.1371/journal.ppat.1005375

61. Assarsson E, Sidney J, Oseroff C, Pasquetto V, Bui HH, Frahm N, et al. A quantitative analysis of the variables affecting the repertoire of $\mathrm{T}$ cell specificities recognized after vaccinia virus infection. J Immunol. (2007) 178:7890-901. doi: 10.4049/jimmunol.178.12.7890

62. Backert L, Kohlbacher O. Immunoinformatics and epitope prediction in the age of genomic medicine. Genome Med. (2015) 7:119. doi: 10.1186/s13073-015-0245-0

63. Oseroff C, Sidney J, Kotturi MF, Kolla R, Alam R, Broide DH, et al. Molecular determinants of $\mathrm{T}$ cell epitope recognition to the common timothy grass allergen. J Immunol. (2010) 185:943-55. doi: 10.4049/jimmunol.1000405

64. Paninabordignon P, Tan A, Termijtelen A, Demotz S, Corradin G, Lanzavecchia A. Universally immunogenic T-cell epitopes - promiscuous binding to human mhc class-ii and promiscuous recognition by T-cells. Eur J Immunol. (1989) 19:2237-42. doi: 10.1002/eji.1830191209

65. Aberle JH, Schwaiger J, Aberle SW, Stiasny K, Scheinost O, Kundi $\mathrm{M}$, et al. Human $\mathrm{CD} 4(+) \mathrm{T}$ helper cell responses after tick-borne encephalitis vaccination and infection. PLoS ONE. (2015) 10:e140545. doi: 10.1371/journal.pone.0140545

66. Oliphant T, Engle M, Nybakken GE, Doane C, Johnson S, Huang L, et al. Development of a humanized monoclonal antibody with therapeutic potential against West Nile virus. Nat Med. (2005) 11:522-30. doi: 10.1038/nm1240

67. Kaufmann B, Vogt MR, Goudsmit J, Holdaway HA, Aksyuk AA, Chipman PR, et al. Neutralization of West Nile virus by cross-linking of its surface proteins with Fab fragments of the human monoclonal antibody CR4354. Proc Natl Acad Sci USA. (2010) 107:18950-5. doi: 10.1073/pnas.1011036107

68. Surman S, Lockey TD, Slobod KS, Jones B, Riberdy JM, White SW, et al. Localization of CD4+ T cell epitope hotspots to exposed strands of HIV envelope glycoprotein suggests structural influences on antigen processing. Proc Natl Acad Sci USA. (2001) 98:4587-92. doi: 10.1073/pnas.071063898
69. Brown SA, Stambas J, Zhan XY, Slobod KS, Coleclough C, Zirkel A, et al. Clustering of Th cell epitopes on exposed regions of HIV envelope despite defects in antibody activity. J Immunol. (2003) 171:4140-8. doi: 10.4049/jimmunol.171.8.4140

70. Sercarz EE, Maverakis E. Mhc-guided processing: binding of large antigen fragments. Nat Rev Immunol. (2003) 3:621-9. doi: 10.1038/nri1149

71. Allison SL, Schalich J, Stiasny K, Mandl CW, Kunz C, Heinz FX. Oligomeric rearrangement of tick-borne encephalitis-virus envelope proteins induced by an acidic Ph. J Virol. (1995) 69:695-700. doi: 10.1128/JVI.69.2.695-700.1995

72. Miller MA, Ganesan APV, Luckashenak N, Mendonca M, Eisenlohr LC. Endogenous antigen processing drives the primary CD4(+) T cell response to influenza. Nat Med. (2015) 21:1216-22. doi: 10.1038/nm.3958

73. Murray K, Walker C, Herrington E, Lewis JA, McCormick J, Beasley DWC, et al. Persistent Infection with West Nile Virus Years after Initial Infection. J Infect Diseases. (2010) 201:2-4. doi: 10.1086/648731

74. Lanteri MC, O'Brien KM, Purtha WE, Cameron MJ, Lund JM, Owen $\mathrm{RE}$, et al. Tregs control the development of symptomatic West Nile virus infection in humans and mice. J Clin Invest. (2009) 119:3266-77. doi: 10.1172/ JCI39387

75. Lanteri MC, Kaidarova Z, Peterson T, Cate S, Custer B, Wu SQ, et al. Association between HLA class I and class II alleles and the outcome of west nile virus infection: an exploratory study. PLoS ONE. (2011) 6:e22948. doi: 10.1371/journal.pone.0022948

76. Sarri CA, Markantoni M, Stamatis C, Papa A, Tsakris A, Pervanidou D, et al. Genetic contribution of MHC Class II genes in susceptibility to West Nile virus infection. PLoS ONE. (2016) 11:e165952. doi: 10.1371/journal.pone.0165952

77. Sarri CA, Papadopoulos GE, Papa A, Tsakris A, Pervanidou D, Baka $A$, et al. Amino acid signatures in the HLA class II peptide-binding region associated with protection/susceptibility to the severe West Nile Virus disease. PLoS ONE. (2018) 13:e205557. doi: 10.1371/journal.pone. 0205557

Conflict of Interest: BK was employed by company Symptoma GmbH, Vienna, Austria.

The remaining authors declare that the research was conducted in the absence of any commercial or financial relationships that could be construed as a potential conflict of interest.

Copyright (C) 2020 Koblischke, Spitzer, Florian, Aberle, Malafa, Fae, Cassaniti, Jungbauer, Knapp, Laferl, Fischer, Baldanti, Stiasny, Heinz and Aberle. This is an open-access article distributed under the terms of the Creative Commons Attribution License (CC BY). The use, distribution or reproduction in other forums is permitted, provided the original author(s) and the copyright owner(s) are credited and that the original publication in this journal is cited, in accordance with accepted academic practice. No use, distribution or reproduction is permitted which does not comply with these terms. 